\title{
Challenges of developing an online Construction Module
}

\author{
Dr Daisy Nwaozuzu and Dr Effie Mpakati-Gama \\ School of Energy, Construction and Environment, \\ Coventry University, Coventry, \\ United Kingdom.
}

\begin{abstract}
.
In this digital era, Learning institutions are utilizing the technical knowhow to promote teaching using virtual learning environments. Learning approaches have developed over the years from traditional face to face (Physical classroom) to Virtual classroom and most recently, a hybrid using an online learning environments to provide a blended learning. The literature demonstrates a wide range of learning platforms such as digital multi user interactive systems, Future Learn and others which promote the Massive Open Online Learning (MOOC) strategy in Education. There has been extensive research on learners and digital learning, learning spaces and their associated problems. Much literature also demonstrates studies on the social science subjects but limited literature in Science, Technology, Engineering, and Mathematics (STEM), with particular reference in Construction Management. Furthermore, few researchers have explored the challenges encountered while developing online construction Modules. The main objectives of the paper are to showcase best practice in designing an online course for universities to emulate, create awareness of the trends in developing an online Construction Module, address the technical challenges in designing an online course, and to identify opportunities for improvement in virtual course learning design for STEM subjects. The paper which is underpinned by social learning and social constructivist theory is based on authors experience in developing such course for a UK university using the Future Learn learning platform. Although several issues were observed, this paper concentrates on the challenges from a course developer and learning designer's perspective on designing a Construction Module learning content using the Future Learn platform. Addressing the issues contributes to the promotion of good practice in the development of future MOOC courses and Advancement of teaching and learning at higher education in UK and beyond.
\end{abstract}

Keyword: Online Learning environment, Learning design, Course developer, Construction Module

\section{Introduction:}

The ubiquity of information and communication technology has made online learning in the UK and beyond a reality to most individuals and higher institutions. Borne out of extensive research [1],[2],[3],[4], [5], hinged on principles of education and made possible through the ubiquity of information and communication technology, online learning has been effective at bridging the knowledge divide arising from busy lifestyle associated with modern society, thereby demonstrating that higher education is not limited to physical space or geographical location. The general belief that Online learning is the future of Higher education is no longer novel, with Universities around the globe investing heavily in the different educational platforms for the delivery of online degrees. The associated flexibility responsible for the surging prominence have made education more attractive to both active and passive learners [6], [7], digital natives and digital immigrant with the social platforms even adding to its sustained growth.

In construction management, just as in other built environment courses, online learning is aimed at effectiveness and efficiency of the learning content. The reliance on the embedded interactive design and the simulated real life activities makes it possible for learners to access learning materials from the comfort of their private space and pace of assimilation. Platforms such as CORE-Materials, Cousera, FutureLearn, Jorum and MIT Open Courseware are already associated with free tuition, thus resulting 
in the availability of lecture content on Construction management as well as other Architectural Engineering courses. These platforms have witnessed an increase in the number of traditional learners seeking to enhance their knowledge base. However, there are identified technical and pedagogical issues with the platforms, although the aspect of content quality of online courses has been explored further by scholars [8], [9], [10]. Other identified issues include communication, technology, time management, pedagogy and assessment.

While some Institutions have tried to provide resources for collaboration on curriculum development as a way of addressing the quality issues around the developed content, others have tried to explore partnership with social learning companies as a novel style in collaboration which is aimed at revolutionising the current style of teaching within universities in the UK. Although this later move has had an early recorded success, it is not without challenges, particular from the perspectives of a course developer. The purpose of this paper therefore is to highlight some of the associated challenges of developing an online construction course through a social learning educational company, and reveal some lessons of best practice learned from the paradigm shift.

\section{Methodology:}

To achieve the purpose of this study, an interpretive research strategy was employed. As a philosophical ideology which promotes the idea that people are deliberate and creative in their actions and actively construct their social world, this strategy considers the dynamic and changing nature of the society and understands that there could be multiplicity of events with different interpretations by different individuals. The associating approach of qualitative interviews was conducted involving three course developers and four learning designers who had previously worked on various learning platforms other than FutureLearn but presently involved in developing a construction course using the FutureLearn platform. Data was analysed using thematic analysis and recommendations were made accordingly. Adapting to the definition of online learning by [11], Online learning in this context refers to postsecondary and credit bearing coursework delivered through the learning management systems such as Moodle and through social learning platform such as FutureLearn, with the aim of providing learning through Social interactions.

\subsection{Social Learning theory:}

Social learning theory offers an opportunity for learning to take place through collaborative learning with learners sharing new knowledge, activities of learning and other resources for learning among themselves. Most higher institutions around the globe adopts Social learning as the ideal organisational learning approach for today's leaners, who are digital natives, either to bridge the gap between knowledge and behaviour change in learners, or to improve team spirits among learners and develop a community of practice. This ideology is applicable both to online and on campus learning.

The philosophy behind the social learning theory is based on the fact that Learning occurs everywhere and anytime and can be socially constructed. A typical example can be demonstrated when we observe others perform certain activities or interact with them, and observe the consequences of their behaviour. The internalised ideas from our observation which then becomes new knowledge forms a basis for a new behaviour. Although this can be perceived either as a behaviouristic approach to learning, or active learning through engagement of observed content, but learners can co-create within the community that they are interacting from. This aspect of social perspectives is inclusive, and involves 'talking, thinking and feeling' [12], as attributes of online Some identified principles that had influenced the selection and implementation of learning tools Online. collaborative learning through social learning has made it possible for learning to be taking place socially by motivating group of learners contribute to a common subject through conversations and discussions. Collaborative reading, presentation and Discussion boards / threaded are some of the proven ways that improves collaborative learning online while motivating students at the same time progressive inquiry often enhanced through formative assessment has also proven to be useful in knowledge building and retention thereby supporting inquiry based learning approach [12]. The embedded interactive apps and video contents, blogs and other interactive contents makes it possible for learners to initiate an inquiry and get an immediate response. By so doing, knowledge is being built. With this in mind course development also considers the generic 
skills that are to be acquired from the designed engaging content, the collaborative knowledge that can be derived from facilitation.

\section{Findings and discussion:}

The FutureLearn platform is a known platform associated with free tuition. As a platform for delivering educational courses, it reviews, and utilizes all aspect of the principle of social learning theory taking into consideration, the cognitive process of learning where the learner is an active participant and facilitator of learning. However as newly proposed platform for robust online learning leading to an award of a degree, challenges associated with changes in operations were inevitable.

\subsection{Challenges:}

The initial challenges were in communication between the Online staff and the academic staff, having been differentiated based on their roles in the development of the online learning. As designing and creating of an online academic content requires time for collaboration, synergy between the campus based academic staff and the learning designers needs to be firmly established in order to actualise the vision of the institution. This is particularly important as the online course programme builds on the success of the institutions existing face-to-face module which are now designed with interactive elements to fit the flexibility that the online learning provides, yet, still aligned to the learning objectives of the on-campus modules. However, the delay in communicating this vision with the expected clarity to the academic staff involved in the online cohort, impacted on the development time, and the actual developed content at the onset, although lessons were learned from this preliminary challenge.

The accessibility of the developed content to diverse learners was identified as a challenge. There is an expectation of a robust design which should accommodate all categories of individuals including learners that are identified as disabled and others with special learning needs. Some common or associating ailment with disability as known in the higher education system includes colour blindness, motor impairment, visual impairment, hearing impairment and Dyslexia. Some settings of the platform were by default suitable for some of this group - learners with Dyslexia and visual impairment. For instance, placing salient points in bullet point, allowing ample white spaces on the page, simple formats in the form of short and concise headings which were already associated with the FutureLearn platform for best practice was considered a favourable development. However, an addition to these best practices could have been in the plurality of formats for contribution to the discussion thread by these group of learners. For instance, allowing audio files like podcast as an acceptable means of joining in the discussion or commenting on an activity was a positive way to increase the number of participants joining the conversation.

Another challenge was on incorporating reflexivity and reflective teaching in the developed content. As with face to face teaching, reflections from previous unit lessons can be accommodated in the next lesson and these reflections can come from either the students, lecturers or both. With the development of online modules, content writing and development are completed before the launch of the course and this does not give room for the gradual reflections that take place while facilitation is ongoing in face to face settings. Admittedly, the FutureLearn platform recognises the importance of reflections in learning and have made provisional step in the learning design to capture students' reflection either at the end of the modules and course but none for the academic developer of the course

\subsection{Suggested approaches:}

Time is an important factor in the development of an online module just as required in any welldeveloped and designed lesson. The general trend as reported by [13] is that online developers has consistently flagged up insufficient development time for online content as a major challenge, most of which are attributable to new content, new technologies, and devising ways of engaging the online learner. 
In order to shed off the burden of time required for the development of the online content, collaboration of the content writer, learning designer, media producer in thinking through some important elements of the online course from a learners' perspective is crucial. This includes decisions on a suitable media content supporting the learning steps within the design. Other important aspect includes collaboration opportunities for leaners, communication protocols, clear performance expectations and opportunities to choose assignment mode as contextualised to construction.

Taking account of the student expectation of an online course and their usage (either based on previous content) should be considered useful in developing a new online learning content. This was found lacking in the project experiences shared above, probably due to the lack of a pilot study of the developed content among students, or the fact that it is a new experience. Although there are provisions for content review, feedback and reflection steps in the learning design framework as integral part of the developed module, the timing of some of such activities hasn't been very effective as it ought to have been. A more realistic approach would involve funding of pilot test of contents and systematically introducing the content as part of a blended learning before full launch online. This will provide an opportunity to engage with the feedback from the pilot exercise.

\section{Conclusion:}

It is desirable for a learning content to be inclusive of students with additional needs in such a way that reduces isolation but improves personalization and mentoring, thus enhancing personalisation as documented by [14] on the need for a 'just for me' approach to learning which is feasible and 'predicated on the power of new technologies [14, p. 32]. However, the experiences so far hasn't delivered this perfectly to accommodate all kinds of additional education needs of these group of students. This may be down to unawareness of the varying disabilities that have been identified among student which could be made overtly realistic if the content is piloted.

Some identified ways for adaption in addressing the challenges highlighted in the text has been through progressive intellectual engagement with learning designers and the media team. Others include collaboration with academics who deliver similar module on campus as well as collaboration with students attending on-campus lectures who may be in the best position to review an online course from a student perspective, thereby highlighting as well as contributing to what should enthuse students in order to engage in online learning [15].

\section{References:}

[1] G. Salmon. E-tivities: The key to active online learning. Routledge, 2013.

[2] K. Swan, Learning effectiveness online: What the research tells us. Elements of quality online education, practice and direction, 2003, Vol. 4(1), pp.13-47.

[3] J. Larreamendy-Joerns and G. Leinhardt, Going the distance with online education. Review of educational research, 2006, Vol. 76(4), pp.567-605.

[4] T. Anderson, The theory and practice of online learning. Athabasca University Press, 2008.

[5] R.M. Wallace, Online learning in higher education: A review of research on interactions among teachers and students. Education, Communication \& Information, 2003, Vol 3(2), pp.241-280

[6] I. Luyt, Bridging spaces: Cross-cultural perspectives on promoting positive online learning experiences. Journal of Educational Technology Systems, 2003, Vol. 42: 3-20.

[7] G. D. Konetes, Distance education's impact during economic hardship: How distance learning impacts educational institutions and businesses in times of economic hardship. International Journal of Instructional Media, 2011, Vol. 38: 7-15.

[8] A. M. Limperos., M. M. Buckner, R. Kaufmann, B.N. Frisby, Online teaching and technological affordances: An experimental investigation into the impact of modality and clarity on perceived and actual learning. Computers \& Education, 2015, Vol. 83: 1-9.

[9] S. Ko, and S. Rossen, Teaching online: A practical guide, Chicago, IL: Routledge, 2010. 
[10] T. C. Bassoppo-Moyo, Evaluating e-learning: A font-end, process and posthoc approach. International Journal of Instructional Media, 2006, Vol. 33: 7e22.

[11] M. Kebritchi, A. Lipschuetz, and L. Santiague, Issues and challenges for teaching successful online courses in higher education: A literature review. Journal of Educational Technology Systems, 2017, Vol. 46(1), pp.4-29.

[12] K. Hakkarainen. A knowledge-practice perspective on technology-mediated learning. International Journal of Computer-Supported Collaborative Learning, 2009, Vol. 4(2), pp.213-231.

[13] L. Archambault, Identifying and addressing teaching challenges in k-12 online environments. Distance Learning, 2010, Vol 7(2), pp. 13-17. Retrieved from

http://proxy1.ncu.edu/login?url//search.ebscohost.com/login.aspx?direct=true \&db=ofs \&AN=52847127 $\underline{\text { \&site }=\text { eds-live }}$

[14] P. John, and S. Wheeler, (2012). The digital classroom: Harnessing technology for the future of learning and teaching. Routledge

[15] M. Hastie, I. Hung, N. Chen, \& Kinshuk. A blended synchronous learning model for educational international collaboration. Innovations in Education and Teaching International, 2020, Vol. 47(1), pp. 9-24. DOI: 10.1080/14703290903525812 